\title{
Note
}

\section{Rapid, quantitative separation by high-performance liquid chromatography of methylated bases in transfer RNA}

\author{
C. E. SALAS and O. Z. SELLINGER
}

Laboratory of Neurochemistry, Mental Health Research Institute, University of Michigan, Ann Arbor, Mich. 48109 (U.S.A.)

(Received September 27th, 1976)

The biological significance and function of the methylated bases at the polynucleotide level is mainly unknown. Two facts appear to be established, however, viz. (a) an increased activity of tRNA methylases characterizes tissues undergoing rapid development ${ }^{1-4}$ and a variety of cells showing tumorigenic properties ${ }^{5-7}$ and (b) on the other hand, growing cells exhibit changing amounts of selected isoacceptor tRNAs ${ }^{8.9}$ and hence of their overall content of amino acid accepting tRNA with age.

Techniques specific for the detection of methylated bases have been widely used; they cover the range from paper chromatography ${ }^{10}$ to nuclear magnetic resonance $^{11}$, thin-layer chromatography ${ }^{12}$, gas-liquid chromatography ${ }^{13}$, and highperformance liquid chromatography (HPLC) ${ }^{14,15}$. The recent papers by Lakings et $a l^{14}$ and Sen and Ghosh ${ }^{15}$ illustrate the advantages in time and in resolution capacity attained by using HPLC over other methods. However, the stringent necessities of precise buffer gradients and of specific temperature gradients have made these methods rather unsuitable for rapid and routine separations of the methylated purine and pyrimidine constituents of TRNA.

In the present investigation we describe a reliable and rapid technique for the detection and quantitative separation of methylated base constituents of tRNA which requires no special buffer or temperature controls.

\section{MATERIALS AND METHODS}

\section{Apparatus}

$\mu$ Bondapak $/ \mathrm{C}_{18}$, a non-polar material consisting of a monomolecular layen of octadecyltrichlorosilane, commercially available (Waters Assoc., Milford, Mass., U.S.A.) for reversed-phase chromatography, was used to pack the column $(30 \times$ $0.4 \mathrm{~cm}$ I.D.).

A solvent delivery system, equipped with a Model $6000 \mathrm{~A}$ dual piston pump, a Model U6 K universal liquid chromatograph injector, and a Model 440 absorbance detector were from Waters Assoc. The chromatrographic run was recorded on an Omniscribe recorder (Texas Instruments, Austin, Texas, U.S.A.). 


\section{Reagents}

The modified and non-modified bases were obtained from the following sources: Sigma (St. Louis, Mo., U.S.A.) - adenine, cytosine, guanine, uracil, $\mathrm{N}^{6}$ methyladenine, $\mathbf{N}^{6}, \mathrm{~N}^{6}$-dimethyladenine, 5-methylcytosine, pseudouridine, 2-methyladenine, $\mathrm{N}^{2}$-methylguanine, $\mathrm{N}^{2}, \mathrm{~N}^{2}$-dimethylguanine, 1-methylhypoxanthine, and 5methyluracil; Cyclo Chem. (Los Angeles, Calif., U.S.A.)- 1-methylguanine and 7methylguanine.

Triffuoroacetic acid was obtained from Matheson, Coleman \& Bell (East Rutherford, N.J., U.S.A.); ammonium phosphate monobasic from J. J. Baker (Phillipsburgh, N.J., U.S.A.); E. coli tRNA from Schwarz/Mann (Orangeburgh, N.Y., U.S.A.); and S-adenosyl-L-(methyl- ${ }^{14} \mathrm{C}$ ) methionine from Research Product International (Eikhart, Ind., U.S.A.).

Methylation of $E$. coli $t R N A$ in vitro

The methylation of $E$. coli tRNA using brain cortex enzymes and S-adenosyl$\mathrm{L}-\left[\right.$ methyl- $\left.{ }^{14} \mathrm{C}\right]$ methionine has been described elsewhere ${ }^{2,4}$.

Hydrolysis of [methyl $\left.{ }^{14} \mathrm{C}\right] \mathrm{tRNA}$

Trifluoroacetic acid $(1 \mathrm{ml})$ was added to [methyl $\left.-{ }^{14} \mathrm{C}\right] \mathrm{R} \mathrm{RA}$ in a combustion tube $\left(25 \times 1.5 \mathrm{~cm}\right.$ I.D.), sealed under vacuum and incubated at $170^{\circ}$ for $30 \mathrm{~min}$. After hydrolysis trifluoroacetic acid was evaporated under a stream of nitrogen at room temperature and the dry residue stored at $4^{\circ}$ until used.

\section{Chromatographic analysis}

The tRNA hydrolysate containing between $2000-8000 \mathrm{dpm}$ was dissolved in water $(0.03-0.2 \mathrm{ml})$ and applied to the column via the injector septum at room temperature using a 100- $\mu 1$ microsyringe (Precisions Sampling, Baton Rouge, La., U.S.A.). Once the sample had been injected onto the column, the flow-rate was maintained constant at $2 \mathrm{ml} / \mathrm{min}$ throughout all experiments. For the separation of eleven methylated bases, buffer solutions were changed $354 \mathrm{sec}$ after the sample injection. Fractions $(0.2 \mathrm{ml})$ were collected in vials and after adding $4 \mathrm{ml}$ of PCS, a tissue solubilizer-scintillation mixture (Amersham/Searle, Arlington Heights, Ill., U.S.A.), the samples were counted. Counting efficiency was $78 \%$, determined by the channels ratio technique in a Unilux II spectrometer (Searle/Analytic, Arlington Heights, Ill., U.S.A.).

All buffer solutions and samples were filtered through Millipore filters ( $0.45-\mu$ pore size) and degassed in vacuo prior to use.

\section{RESULTS*}

Fig. 1 shows the separation of an artificial mixture of the unmodified base constituents of tRNA using $0.05 M$ ammonium phosphate (pH 5.9) as the eluting

- The abbreviations used are: $m^{2} A=1$-methyladenine; $m^{5} \mathrm{C}=5$-methylcytosine; $m^{1} G=1$ methylguanine; $m^{5} \mathrm{U}=5$-methyluracil; $\mathrm{m}^{2} \mathbf{H y}=1$-methylhypoxanthine; $\mathrm{m}^{7} \mathrm{G}=7$-methylguanine; $\mathrm{m}^{2} \mathrm{~A}=$ 2-methyladenine; $\mathrm{m}^{2} \mathrm{G}=\mathrm{N}^{2}$-methylguanine; $\mathrm{m}^{6} \mathbf{A}=\mathrm{N}^{6}$-methyladenine; $\mathrm{m}_{2}^{2} \mathrm{G}=\mathrm{N}^{2}, \mathrm{~N}^{2}$-dimethylguanine; $m_{6}^{6} A=N^{6}, N^{6}$-dimethyladenine; $U=$ uracil; $C=$ cytosine; $A=$ adenine; $G=$ guanine. 

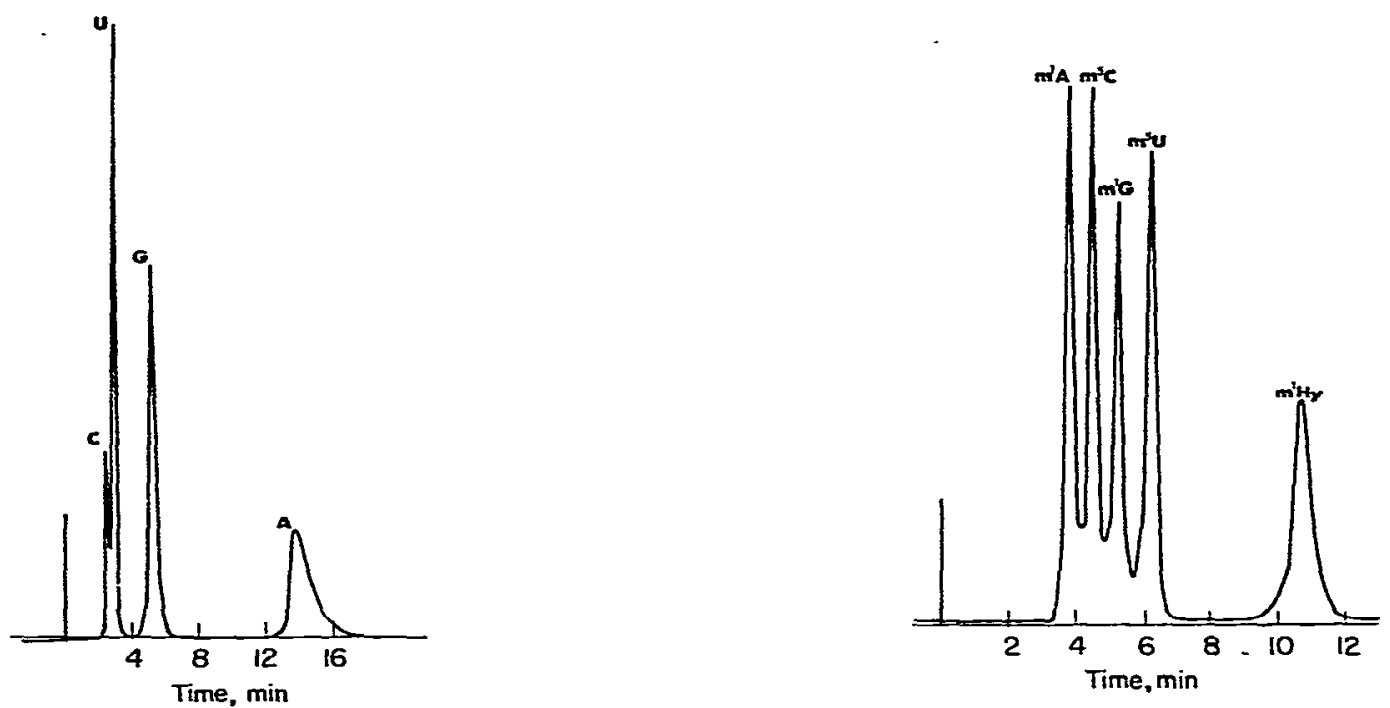

Fig. 1. Separation of an artificial mixture of cytosine, uracil, guanine, and adenine by $\mu$ Bondapak $/ C_{18}$ at a flow-rate of $2.0 \mathrm{ml} / \mathrm{min}$ and a pressure of about 2000 p.s.i. Buffer: $0.05 M$ ammonium phosphate (pH 5.9). The 254-nm detector was set at 0.2 a.u.f.s.

Fig. 2. Separation of an artificial mixture of 1-methyladenine, 5-methylcytosine, 1-methylguauine, 5methyluracil, and 1-methylhypoxanthine by $\mu$ Bondapak/ $C_{18}$. The experimental conditions were the same as described in the legend to Fig. 1.

\section{TABLE I}

SEPARATION OF METHYL BASES BY HIGH-PRESSURE LIQUID CHROMATOGRAPHY ON $\mu$ BONDAPAK/C $/ 1$

The experinental cunditions ale the same as those described in the legend to Fig. 4.

\begin{tabular}{lcc}
\hline Compound & $\begin{array}{l}\text { Retention time } \\
(\text { sec })^{*}\end{array}$ & $\begin{array}{c}\text { Retention vo } \\
\left(\mathrm{ml}^{* *}\right.\end{array}$ \\
\hline 1-Methyladenine & 221 & 7.4 \\
5-Methylcytosine & 264 & 8.8 \\
1-Methylguanine & 306 & 10.2 \\
5-Methyluracil & 359 & $12 . J$ \\
1-Methylhypoxanthine & 630 & 21.0 \\
7-Methylguanine & 684 & 22.8 \\
$\mathrm{~N}^{2}$-Methylguanine & 767 & 25.6 \\
2-Methyladenine & 816 & 27.2 \\
$\mathrm{~N}^{2}, \mathrm{~N}^{2}$-Dimethylguanine & 1327 & 44.2 \\
$\mathrm{~N}^{6}$-Methyladenine & 963 & 32.1 \\
$\mathrm{~N}^{6}, \mathrm{~N}^{6}$-Dimethyladenine & 1683 & 56.1 \\
Cytosine & 144 & 4.8 \\
Uracil & 174 & 5.8 \\
Guanine & 306 & 10.2 \\
Adenine & 718 & 23.9 \\
\hline
\end{tabular}

Retention time was determined as an average from three independent experinients with less than $5 \%$ variation.

* Retention volume values were determined from retention times at a flow-rate of $2 \mathrm{ml} / \mathrm{min}$. 
buffer. Two of them, cytosine and uracil, had the lowest and the next to lowest retention times of all bases tested (Table I), while guanine eluted together with 1-methylguanine. The retention time for adenine coincided with that for 7-methylguanine (Table I).

The separation of the methyl bases into two major groups was attempted next. Fig. 2 depicts the separation of 1-methyladenine, 5-methylcytosine, 1-methylguanine, 5-methyluracil, and 1-methylhypoxanthine using the same buffer as above.

The second group of methyl bases was resolved by using $0.05 \mathrm{M}$ ammonium phosphate ( $\mathrm{pH}$ 3.3). The methylated bases in order of elution were: 7-methylguanine, $\mathrm{N}^{2}$-rnethylguanine, 2-methyladenine, and $\mathrm{N}^{2}, \mathrm{~N}^{2}$-dimethylguanine (Fig. 3). Although not shown in Fig. $3, \mathrm{~N}^{6}$-methyladenine and $\mathrm{N}^{6}, \mathrm{~N}^{6}$-dimethyladenine can also be
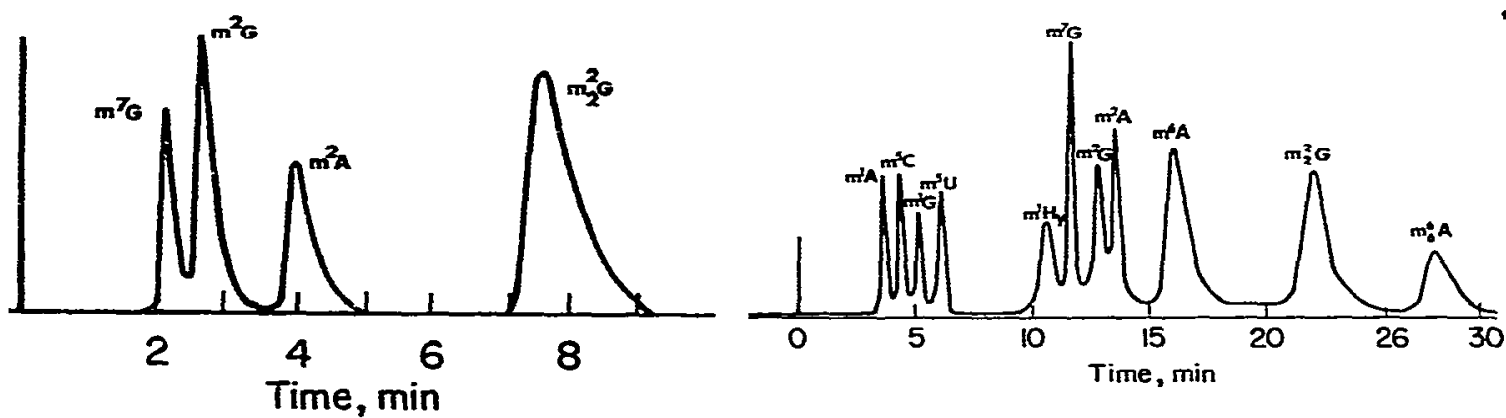

Fig. 3. Separation of an artificial mixture of 2-methyladenine, 7-methylguanine, $\mathbf{N}^{2}$-methylguanine and $N^{2}, N^{2}$-dimethylguanine by $\mu$ Bondapak/ $C_{18}$. The experimental conditions were the same as described in the legend to Fig. 1.

Fig. 4. Separation of a mixture of methylated bases by $\mu$ Bondapak/ $C_{18}$ at a flow-rate of about 2 $\mathrm{ml} / \mathrm{min}$ and about 2000 p.s.i. The elution order was the following: 1-methyladenine, 5-methylcytosine, 1-methylguanine, 5-methyluracil, 1-methylhypoxanthine, 7-methylguanine, $\mathbf{N}^{2}$-methylguanine, 2methyladenine, $\mathbf{N}^{6}$-methyladenine, $\mathbf{N}^{2}, \mathbf{N}^{2}$-dimethylguanine, and $\mathbf{N}^{6}, \mathbf{N}^{6}$-dimethyladenine. The column was equilibrated with $0.05 M$ ammonium phosphate buffer ( $\mathrm{pH}$ 5.9). The 254-nm detector was set at 0.5 a.u.f.s. For detailed explanation, see Materials and methods.

resolved (Table I and Fig. 4). However, neither buffer system alone (pH 3.3 or 5.9) was able to separate the complete mixture of methylated bases.

The optimal conditions for the separation of an artificial mixture of eleven methylated bases were achieved by using the two buffer elution systems described above in series. Fig. 4 illustrates the separation of the eleven methylated bases under these conditions. Increasing the buffer concentration and thus the solvent polarity was ineffective in enhancing the separation.

The linearity of the spectrophotometric response over a range of increasing amounts of a given methyl base was determined for each base. This allowed us to determine for each experiment the actual amount of base present in the samples, plus it gave us the assurance that we were operating below the maximal capacity of the column (Fig. 5).

Amounts as low as $\mathbf{2 0 0}$ pmoles could be detected spectrophotometrically using this technique. Finally, the procedure was used to analyze the [methyl ${ }^{14} \mathrm{C}$ ]base distribution of $E$. coli $B$ tRNA methylated in vitro by a partially purified preparation of tRNA methyltransferases derived from eight-day-old rat brain cortex (Fig. 6). 

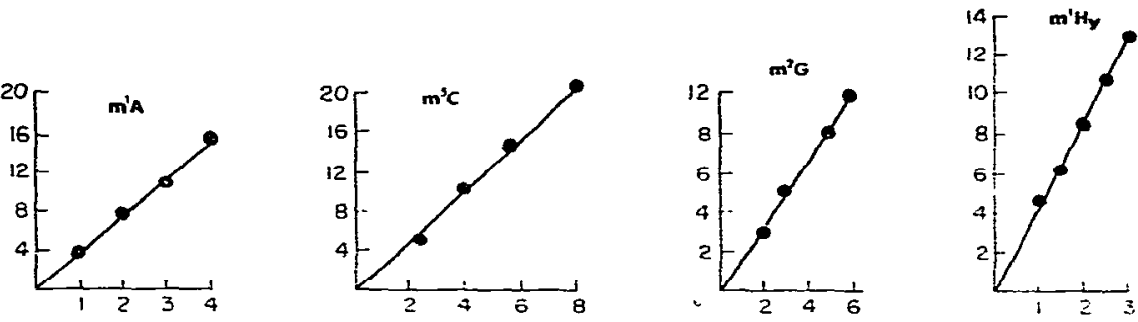

$E$
5
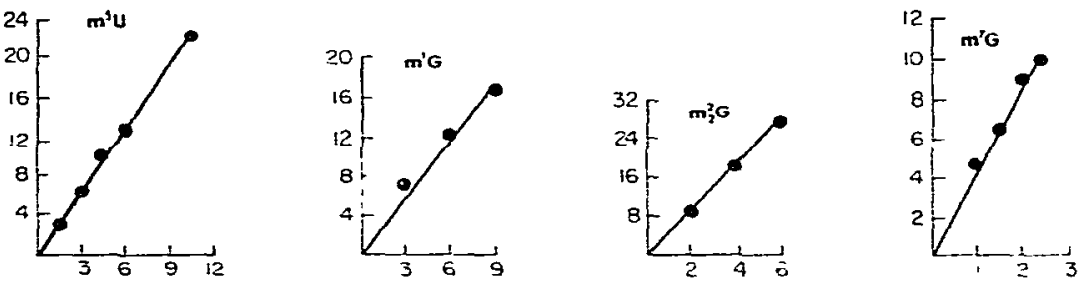

moles $\times 10^{-10}$

Fig. 5. Standardization curves for the methylated bases. The chromatographic conditions were the same as those given in the legend to Fig. 1. $0.05 \mathrm{M}$ ammonium phosphate buffer $(\mathrm{pH} 3.3$ ) was used for the elution of 7 -methylguanine, $\mathrm{N}^{2}$-methylguanine, and $\mathrm{N}^{2}, \mathrm{~N}^{2}$-dimethylguanine. Each point represents an average of two experiments with less than $5 \%$ difference.

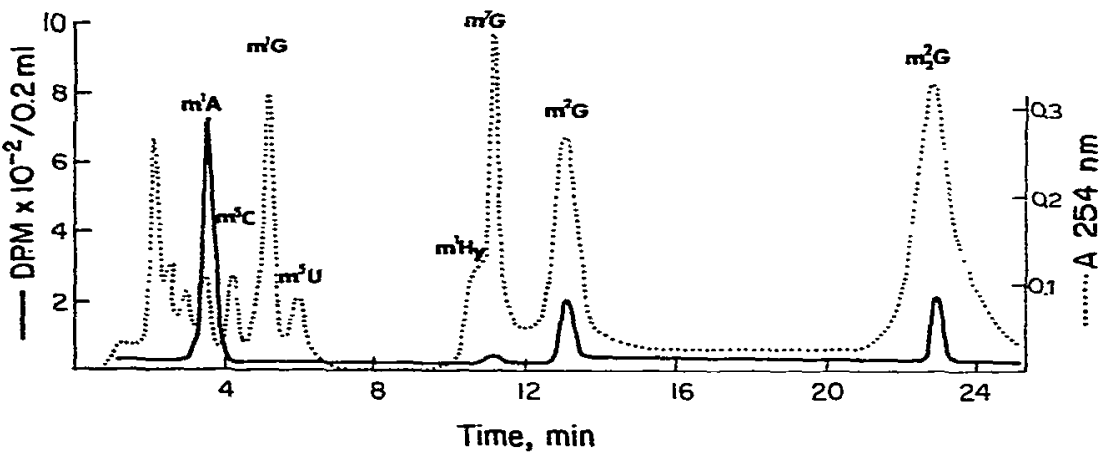

Fig. 6. Analysis of a hydrolysate from $E$. coli [methyl ${ }^{14} \mathrm{C}$ ] tRNA methylated in vitro using brain cortex enzymes'. 1-Methyladenine, 5-methylcytosine, 1-methylguanine, 5-methyluracil, 1-methylhypoxanthine, $\mathrm{N}^{2}$-methylguanine, and $\mathrm{N}^{2}, \mathrm{~N}^{2}$-dimethylguanine were added as carriers. The $254-\mathrm{nm}$ detector was set at 1.0 a.u.f.s. For detailed explanation, see Materials and methods.

The radioactive profile (Fig. 6) indicated that 1-methyladenine, $\mathbf{N}^{2}$-methylguanine, and $\mathbf{N}^{2}, \mathbf{N}^{2}$-dimethylguanine were the only methyl bases formed. The presence of an unknown substance absorbing at $254 \mathrm{~nm}$ which was not radioactive and which had a retention time between $180-200 \mathrm{sec}(6.5 \mathrm{ml}$ ) is also depicted (Fig. 6). Neither pseudouridine nor isopentenyladenine could be associated with this peak since their retention time is similar to that of uracil. 


\section{DISCUSSION}

The separation of eleven methylated bases by reversed-phase HPLC has been successfully achieved using a rapid and easily reproducible technique.

Since the elution pattern is precisely defined in temporal terms, buffer changes and the collection of samples can be adjusted to take place at predetermined time points after sample injection. With the described procedure a complete run, and the total re-equilibration of the column to make it ready for the next run, can be achieved in less than $40 \mathrm{~min}$. The same column has been used for several months without detectable change in resolution.

Neither the column nor the buffer solutions needed any special temperature adjustments. The method proved particularly suitable for the analysis of the [methyl${ }^{14} \mathrm{Cl}$ base distribution of tRNA methylated in vitro in the presence of brain tRNA methyltransferases and S-adenosyl-L-[methyl- $\left.{ }^{14} \mathrm{C}\right]$ methionine.

The procedure also assures quantitation of the separated bases down to the level of 200 pmoles in view of the fact that spectrophotometric analysis assures the proportionality between peak height (or surface area) and the amount of each base injected. Finally, the procedure has been shown to give quantitative recoveries in terms of the ratio between the injected and the recorded absorbance.

\section{ACKNOWLEDGEMENT}

This study was supported in part by grant NS 06294 from the United States Public Health Service.

\section{NOTE ADDED IN PROOF}

Since submitting the manuscript we have been able to separate 3-methylcytosine from the 11 bases mentioned in the text. Its retention time under the conditions of Fig. 6 was determined to be $150 \mathrm{sec}$ and its retention volume $5.0 \mathrm{ml}$.

\section{REFERENCES}

1 L. N. Simon, A. J. Glasky and T. H. Rejal, Biochim. Biophys. Acta, 142 (1967) 99.

2 C. E. Salas, C. J. Cummins and O. Z. Sellinger, Neurochem. Res., 1 (1976) 369

3 G. Guroff and M. Brodsky, J. Neurochem., 18 (1971) 2077.

4 C. J. Cummins, C. E. Salas and O. Z. Sellinger, Brain Res.. 96 (1975) 407.

5 A. E. Pegg and A. M. Hawks, Biochem. J., 137 (1974) 229.

6 E. Tsutsui, P. R. Srinivasan and E. Borek, Proc. Natl. Acad. Sci. U.S., 56 (1966) 1003.

7 K. Randerath, S. K. MacKinnon and E. Randerath, FEBS Lett., 15 (1971) 81.

8 G. Keith, H. Rogg, G. Dirheimer, B. Menichi and T. Heyman, FEBS Lett., 61 (1976) 120.

9 A. Araya, M. Krauskopf and M. A. Q. Siddiqui, Biochem. Biophys. Res. Conmun., 67 (1975) 924.

10 Y. Iwanami and G. M. Brown, Arch. Biochem. Biophys., 124 (1968) 472.

11 L. S. Kan, P. O. P. Ts'o, F. v. d. Haar, M. Sprinzl and F. Cramer, Biochem. Biophys. Res. Commun., 59 (1974) 22.

12 T. W. Munns, K. C. Podratz and P. A. Katzman, Biochemistry, 13 (1974) 4409.

13 D. B. Lakings and C. W. Gehrke, Clin. Chem., 18 (1972) 810.

14 D. B. Lakings, T. P. Waalkes and J. E. Mrochek, J. Chromatogr., 116 (1976) 83.

15 G. C. Sen and H. P. Ghosh, Anal. Biochem., 58 (1974) 578. 